\section{Visual outcome and complications of 25-gauge vitrectomy for rhegmatogenous retinal detachment; 84 consecutive cases}

H Kunikata and K Nishida

\begin{abstract}
Purpose To assess the visual outcome and complications of 25-gauge transconjunctival sutureless vitrectomy (25G-TSV) for rhegmatogenous retinal detachments. Methods Retrospective, consecutive, interventional case series of 84 eyes of 84 consecutive patients with RRD who

the IOP can occur especially in eyes with a preoperative macula-off RRD.

Eye (2010) 24, 1071-1077; doi:10.1038/eye.2010.41; published online 16 April 2010

Keywords: rhegmatogenous retinal detachment; 25-gauge vitrectomy; postoperative complication; redetachment; intraocular pressure
\end{abstract} underwent 25G-TSV. All surgeries were performed by a single surgeon at a single centre.

Results The initial and final reattachment rates were 95.2 and $100 \%$, respectively. The mean visual acuity improved from 0.78 logarithm of the minimum angle of resolution (logMAR) units to $0.17 \log$ MAR units at the final examination $(P<0.001)$. A macula-off RRD was present preoperatively in 45 of the 84 eyes, and 11 of these eyes $(24.4 \%)$ developed postoperative retinal complications. Of these complications, one eye had an intraoperative choroidal detachment, five developed a postoperative macular pucker, one eye had a postoperative macular hole, and four eyes developed a retinal redetachment. The percentages of eyes developing retinal complications in the macula-on group (2.6\%) was significantly lower than that in the macula-off group $(P=\mathbf{0 . 0 0 4})$. An intraocular pressure (IOP) $\geqslant 35 \mathrm{~mm} \mathrm{Hg}$ was detected in five eyes $(6.0 \%)$ within the first postoperative week. All of these eyes had a macula-off RRD, and none of the eyes with a macula-on RRD had an elevation of the IOP $(P=0.04)$.

Conclusions Our findings indicate that 25G-TSV is a feasible treatment for RRD and leads to retinal reattachment rates comparable with those following conventional vitrectomy. However, intra- and postoperative retinal complications and postoperative elevation of

\section{Introduction}

Until recently, the standard treatments of rhegmatogenous retinal detachments not amenable to pneumatic retinopexy were scleral buckling and 20-gauge pars plana vitrectomy (20G-PPV). ${ }^{1}$ However, the conjunctival surface is disrupted during both procedures, and many patients complain of postoperative ocular irritation and pain from the scarred conjunctiva.

Twenty-five gauge transconjunctival sutureless vitrectomy (25G-TSV) was first reported in 2002, and this sutureless technique has been commonly used throughout the world. ${ }^{2,3}$ Two clinical studies on patients with vitreoretinal diseases, for example, epiretinal membrane, who underwent vitrectomy reported that the postoperative conjunctival injection and postoperative pain and discomfort were significantly less following 25G-TSV than after 20G-PPV. ${ }^{4,5}$ The increase in popularity of the 25G-TSV was enhanced by the clinical studies showing significant reductions in conjunctival injection and postoperative pain and discomfort. Thus, the main advantage of 25G-TSV is that a sutured sclerotomy is not needed intraoperatively, which would then reduce the postoperative ocular irritation and discomfort from the scarred conjunctiva.

Although the indications for 25G-TSV have increased for different vitreoretinal diseases
Department of

Ophthalmology and Visual Science, Tohoku University Graduate School of Medicine, Sendai, Japan

Correspondence:

H Kunikata,

Department of

Ophthalmology and Visual Science,

Tohoku University Graduate School of Medicine,

1-1 Seiryo-machi, Aoba-ku, Sendai 980-8574, Japan.

Tel: + 81227177294 ;

Fax: +8122717 7298

E-mail: kunikata@

oph.med.tohoku.ac.jp

Received: 7 May 2009

Accepted in revised form:

11 March 2010

Published online:

16 April 2010 
including pediatric cases, ${ }^{6}$ complications such as intraoperative suprachoroidal hemorrhage and postoperative endophthalmitis have been also reported..$^{7-9}$ There are only two reports with a relatively large number of cases that used 25G-TSV as the primary procedure for treating the RRD, viz., Lai et al with 53 consecutive eyes of 52 patients, and Von Fricken et al with 61 consecutive eyes of 61 patients. ${ }^{10,11}$ In the other reports using 25G-TSV for the RRD, the number of cases was small (10-20 cases). ${ }^{12-18}$

The purpose of this study was to determine the visual outcome and retinal complications of 84 consecutive eyes with a RRD treated by 25G-TSV. All of the surgeries were performed by a single surgeon at a single hospital.

\section{Patients and methods}

\section{Subjects}

We performed retrospective analyses of the medical records of 84 eyes of 84 consecutive patients with a RRD who had undergone pars plana vitrectomy using a 25-G trocar cannula system (Alcon Laboratories; Fort Worth, Texas, USA). The preoperative demographics of the patients are shown in Table 1. All of the surgeries were performed at the Surgical Retina Clinic of the Tohoku University Hospital from August 2006 through January 2008. The inclusion criteria were; rhegmatogeous retinal detachments and patients admitted to our hospital and treated by a single surgeon (HK). The exclusion criteria were; previous scleral buckling or vitrectomy, trauma and eyes with complex vitreoretinal disease such as proliferative vitreoretinopathy (PVR) and giant RRD. After the purpose and procedures of the operation were explained, an informed consent was obtained from all patients. The procedures conformed to the tenets of the Declaration of Helsinki.

\section{Surgical procedures}

All surgeries were performed under retrobulbar anaesthesia using the oblique sclerotomy technique, and were performed using the Accurus Vitrectomy System (Alcon Laboratories, Fort Worth, TX, USA). ${ }^{19,20}$ Lenses that were cataractous were extracted before the vitrectomy. After resecting the vitreal core, a $4 \mathrm{mg}$ suspension of triamcinolone acetonide (TA; Kenakort-A. Bristol Pharmaceuticals KK, Tokyo, Japan) was injected into the vitreous to determine if a posterior vitreous detachment (PVD) was present. If a PVD was present, we examined to see if undetached cortical vitreous was present between the retina and vitreous. The peripheral vitreous was shaved as much as possible with scleral
Table 1 Preoperative characteristics, operative, visual and anatomical outcomes of 84 eyes undergoing primary 25-G transconjunctival sutureless vitrectomy possibly associated visual acuity improvement

\begin{tabular}{|c|c|c|}
\hline & Number $(\%)$ & P-value \\
\hline Eye affected & & $0.53^{\mathrm{a}}$ \\
\hline Right & $40(47.6)$ & \\
\hline Left & $44(52.4)$ & \\
\hline $\operatorname{Sex}$ & & $0.04^{\mathrm{a}}$ \\
\hline Male & $46(54.8)$ & \\
\hline Female & $38(45.2)$ & \\
\hline Age (years) & & $0.80^{\mathrm{b}}$ \\
\hline Mean \pm SD & $60.3 \pm 11.9$ & \\
\hline Median & 59 & \\
\hline Range & 26 to 84 & \\
\hline No. of preoperative pseudophakia & $18(21.4)$ & $0.59^{\mathrm{a}}$ \\
\hline PreoperativeVA $\pm S D(\log M A R)$ & $0.78 \pm 0.81$ & $<0.001^{\mathrm{b}}$ \\
\hline Final VA \pm SD (logMAR) & $0.17 \pm 0.34$ & $0.27^{\mathrm{b}}$ \\
\hline VA improvement (logMAR) & $0.61 \pm 0.69$ & - \\
\hline Triple surgery & $55(65.5)$ & $0.57^{\mathrm{a}}$ \\
\hline Mean number of $\mathrm{RB} \pm \mathrm{SD}$ & $2.0 \pm 1.4$ & $0.42^{\mathrm{a}}$ \\
\hline One & $39(46.4)$ & \\
\hline Two or more than two & $45(53.6)$ & \\
\hline Macula status & & $<0.001^{\mathrm{a}}$ \\
\hline Macula-on & $39(46.4)$ & \\
\hline Macula-off & $45(53.6)$ & \\
\hline \multicolumn{3}{|l|}{ Mean operative time (min, range) } \\
\hline Mean \pm SD & $50.4 \pm 15.7$ & $0.20^{\mathrm{b}}$ \\
\hline Range & 26 to 108 & \\
\hline Intraoperative triamcinolone acetonide & $84(100)$ & - \\
\hline Need suturing at surgery end & $0(0)$ & - \\
\hline Preoperative PVD & $82(97.6)$ & $0.41^{\mathrm{a}}$ \\
\hline Residual cortical vitreous in PVD eyes & & $0.82^{\mathrm{a}}$ \\
\hline Exist & $17 / 82(20.7)$ & \\
\hline None & $65 / 82(79.3)$ & \\
\hline Initial anatomical success & $80(95.2)$ & $0.32^{\mathrm{a}}$ \\
\hline Final anatomical success & $84(100)$ & - \\
\hline \multicolumn{3}{|l|}{ Follow up periods (mo) } \\
\hline Mean \pm SD & $6.6 \pm 3.7$ & $0.001^{\mathrm{b}}$ \\
\hline Range & 3 to 18 & \\
\hline
\end{tabular}

$\log \mathrm{MAR}$, logarithm of the minimum angle of resolution; PVD, posterior vitreous detachment; $R B$, retinal break; Triple surgery, phacoemulsification and aspiration, intraocular lens implant, and 25-G transconjunctival sutureless vitrectomy; VA, visual acuity

aMann-Whitney $U$-test.

'Spearman's correlation coefficient by rank test.

indentation. After the shaving of the peripheral gel, fluid-gas exchange was performed, and endophotocoagulation was performed around all retinal tears. Sulfur hexafluoride (SF6) or perfluoropropane (C3F8) was injected for intraocular tamponade. Antibiotics and corticosteroids were injected subconjunctivally postoperatively in all cases. 


\section{Clinical findings}

The best-correct visual acuity (BCVA) was measured using the Landolt $C$ visual acuity chart, and the decimal acuities were converted to the logarithm of the minimal angle of resolution ( $\log$ MAR) units. For statistical analyses, counting fingers vision was set to $2.0 \log \mathrm{MAR}$ units and hand motion vision was set to $3.0 \log$ MAR units.

All of the patients had a complete ophthalmological examination at 3 or more months after the surgery. The outcome measures investigated were initial anatomical success rate, final anatomical success rate, postoperative visual acuity, postoperative intraocular pressure (IOP), and the intra- and postoperative complications. An anatomical success after the initial surgery was defined as a complete reattachment of the retina when all of the gas in the eye had disappeared. The final anatomical success was defined as a complete reattachment at 3 months after the surgery.

\section{Statistical analyses}

The preoperative, intraoperative and postoperative factors that we assessed as possibly affecting the results were investigated using statistical packages including Mann-Whitney $U$-test and Spearman's correlation coefficient by rank test.

The operative time, anatomical success, intra- and postoperative retinal complication of 25G-TSV for the RRD according to whether the preoperative macula was attached or not attached were compared using the Mann-Whitney $U$-test, Fisher's exact probability test and $\chi^{2}$ for independence test.

\section{Results}

The preoperative, intraoperative and postoperative factors that could influence visual acuity are shown in Table 1 . There were 46 men and 38 women whose mean \pm SD age was $60.3 \pm 11.9$ years. Their preoperative BCVA was $0.78 \pm 0.81 \log \mathrm{MAR}$ units and ranged from -0.18 to $3.0 \log$ MAR units. The mean follow-up period was $6.6 \pm 3.7$ months with a range of 3 to 18 months. The initial and final anatomical success rates were 95.2 and $100 \%$, respectively. The mean final BCVA was $0.17 \pm 0.34$ logMAR units, which was significantly better than the preoperative BCVA of $0.78 \pm 0.81 \log$ MAR units $(P<0.001$, Wilcoxon's signed-rank test). The postoperative BCVA was significantly correlated with the preoperative BCVA ( $r=0.70, P<0.001$, Spearman's correlation coefficient by rank). The BCVA in 47 of the 84 eyes $(56.0 \%)$ improved by $>0.2 \log$ MAR units.
A posterior vitreous detachment (PVD) was detected intraoperatively in 82 of the $84(97.6 \%)$ eyes. A strand of undetached cortical vitreous was observed after the injection of TA in 17 of the $82(20.7 \%)$ eyes with a PVD. The mean number of retinal tears was $2.0 \pm 1.4$, and the mean operative time was $50.4 \mathrm{~min}$ for phacoemulsification and aspiration (PEA), intraocular lens implant (IOL) and 25G-TSV (PEA + IOL + 25G-TSV; triple surgery) in 55 eyes $(65.5 \%)$. The proportion of triple surgery was not significantly different between macula-on and macula-off $\operatorname{RRD}\left(P=0.48, \chi^{2}\right.$ for independence test). None of the patients required a suturing of the sclerotomy site at the end of the initial surgery.

The visual improvement was better in the eyes with a preoperative macula-off detachment than with a macula-on RRD ( $P<0.001$; Mann-Whitney $U$-test). The preoperative age $(P=0.86$, Mann-Whitney $U$-test $)$, $\log$ MAR visual acuity $(P=0.16$, Mann-Whitney $U$-test), incidence of macula-off $\operatorname{RRD}\left(P=0.14, \chi^{2}\right.$ for independence test), and concurrent cataract extraction $\left(P=0.60, \chi^{2}\right.$ for independence test) were not significantly different between men and women. However, the visual improvement was better in men than women ( $P=0.04$; Mann-Whitney $U$-test). In the eyes with a macula-off RRD, there was no significant difference in the visual improvement between men and women ( $P=0.34$, Mann-Whitney $U$-test), and also no significant difference in the visual improvement between those who had triple surgery and those who had only 25G-TSV ( $P=0.53$, Mann-Whitney $U$-test). The visual improvement was significantly correlated with the preoperative BCVA $(r=0.83 ; P<0.001)$ and the follow-up periods $(r=0.36 ; P=0.001$; Spearman's correlation coefficient by rank test) for all 84 patients. In eyes with a preoperative macula-off RRD there was a significant correlation in the visual improvement and preoperative BCVA $(r=0.77 ; P<0.001$, Spearman's correlation coefficient by rank test). In addition, there was a significant difference in the postoperative visual acuity at 1 month and 3 months $(P=0.01$; Wilcoxon's signed-rank test).

The operative time, anatomical success rate, intra- and postoperative retinal complications of eyes with either a preoperative macula-on or macula-off condition that underwent 25G-TSV for RRD are shown Table 2. Forty-five of the 84 eyes (53.6\%) had a macula-off detachment preoperatively, and the mean operative time in these eyes was significantly longer than that of eyes with a macula-on RRD $(P=0.009$, Mann-Whitney $U$-test). Eleven of the eyes with a macula-off RRD developed retinal complications (24.4\%); one eye had an intraoperative choroidal effusion, five eyes developed a postoperative macular pucker, one eye developed 
Table 2 Operative time, anatomical success, postoperative IOP, intra- and postoperative retinal complication of 25-G transconjunctival sutureless vitrectomy for rhegmatogenous retinal detachment by preoperative macula status

\begin{tabular}{|c|c|c|c|c|}
\hline & Overall & Macula-on retinal detachment & Macula-off retinal detachment & P-value \\
\hline Number of eyes & 84 & 39 & 45 & - \\
\hline Operative time (min, $\pm \mathrm{SD}$ ) & $50.4 \pm 15.7$ & $45.4 \pm 12.2$ & $54.7 \pm 17.1$ & $0.009^{\mathrm{a}}$ \\
\hline \multicolumn{5}{|l|}{ Anatomical success, no. (\%) } \\
\hline Initial anatomical success & $80(95.2)$ & $39(100)$ & $41(91.1)$ & $0.08^{\mathrm{b}}$ \\
\hline Final anatomical success & $84(100)$ & $39(100)$ & $45(100)$ & - \\
\hline Postoperative IOP $(\mathrm{mm} \mathrm{Hg}, \pm S D)$ & $16.2 \pm 9.7$ & $14.7 \pm 7.4$ & $17.5 \pm 11.2$ & \\
\hline $\mathrm{OH}(>$ or $=35 \mathrm{~mm} \mathrm{Hg})$, no. $(\%)$ & $5(6.0)$ & $0(0)$ & $5(11.1)$ & $0.04^{\mathrm{b}}$ \\
\hline Hypotony $(<$ or $=5 \mathrm{~mm} \mathrm{Hg}$ ), no. $(\%)$ & $9(10.7)$ & $4(10.3)$ & $5(11.1)$ & $0.59^{\mathrm{b}}$ \\
\hline \multicolumn{5}{|l|}{ Retinal complication, no. (\%) } \\
\hline Intraoperative choroidal effusion & $1(1.2)$ & $0(0)$ & $1(2.2)$ & $0.54^{\mathrm{b}}$ \\
\hline Postoperative macular pucker & $6(7.1)$ & $1(2.6)$ & $5(11.1)$ & $0.14^{\mathrm{b}}$ \\
\hline Postoperative macular hole & $1(1.2)$ & $0(0)$ & $1(2.2)$ & $0.54^{\mathrm{b}}$ \\
\hline Redetachment & $4(4.8)$ & $0(0)$ & $4(8.9)$ & $0.08^{\mathrm{b}}$ \\
\hline Total & $12(14.3)$ & $1(2.6)$ & $11(24.4)$ & $0.004^{c}$ \\
\hline
\end{tabular}

$\mathrm{IOP}$, intraocular pressure; $\mathrm{OH}$, ocular hypertension.

a Mann-Whitney U-test.

'Fisher's exact probability test.

${ }^{c} \chi^{2}$ for independence test.

a postoperative macular hole, and four eyes had a redetachment of the retina. One eye with a macula-on RRD developed a postoperative macular pucker (2.6\%). Six eyes developed a macular pucker; five in the preoperative macula-off RRD group and one in the macula-on RRD group.

Four of these six eyes with a macular pucker and one eye with a macular hole were treated surgically several months after the first operation and each recovered.

The intraoperative choroidal effusion resolved spontaneously after the operation. A second vitrectomy with 20-G instruments was performed on the four eyes with a postoperative redetachment and a reattachment was attained without the use of silicon tamponade in all eyes.

The percentage of retinal complications in the macula-on eyes was significantly lower than the percentage in eyes with a preoperative macula-off $\operatorname{RRD}\left(P=0.004 ; \chi^{2}\right.$ for independence test).

Nine $(10.7 \%)$ of the 84 eyes were hypotonic (IOP $\leqslant 5 \mathrm{~mm} \mathrm{Hg}$ ) within the first postoperative week but all resolved spontaneously. Five of these eyes with a reduced IOP belonged to the preoperative macula-off RRD group and four eyes belonged to the macula-on group ( $P=0.59$, Fisher's exact probability test).

Nineteen eyes $(22.6 \%)$ had an elevated $\mathrm{IOP} \geqslant 21 \mathrm{~mm} \mathrm{Hg}$ within the first week. Six of these eyes belonged to the preoperative macula-on RRD group and 13 eyes to the macula-off RRD group ( $P=0.11$, Fisher's exact probability test). In addition, an IOP $\geqslant 35 \mathrm{~mm} \mathrm{Hg}$ was detected in five eyes $(6.0 \%)$ within the first postoperative week, and all of these eyes belonged to the macula-off group ( $P=0.04$, Fisher's exact probability test). All of the eyes with an elevated IOP were treated with antihypertensive eye drops, and the IOPs returned to normal levels without glaucoma surgery.

The characteristics of the four eyes that had a retinal redetachment after the initial 25G-TSV are shown in Table 3. Only one break was found at the initial examination in these eyes. Four of these eyes developed a retinal redetachment within 2 months (mean 25.0 days, range 11-61 days) after the initial surgery. The redetachment was due to an opening of the original retinal break in 2 eyes, a subretinal strand proliferation in one eye, and a new retinal break in one eye. Residual peripheral vitreous was detected in these four cases during the second vitrectomy.

\section{Discussion}

Our results showed that 25G-TSV was effective in reattaching the retina, and the incidence of retinal complications was significantly higher in eyes with a preoperative macula-off RRD than a macula-on RRD. In addition, a redetachment of the retina was found in four eyes, and they were all in the macula-off RRD group. All of the redetachment occurred within 2 months of the initial surgery.

Oshima et al and Miki et al reported that the initial success rate of 20G-PPV was over $90 \%$, which was comparable with that of scleral buckling ${ }^{21,22}$ We achieved 
Table 3 Characteristics, operative details and postoperative course of four patients with redetachment after 25-G transconjunctival sutureless vitrectomy

\begin{tabular}{llllllllllllll}
\hline $\begin{array}{l}\text { Patient } \\
n o .\end{array}$ & Eye & Age & Gender & $\begin{array}{c}\text { Lens } \\
\text { status }\end{array}$ & $\begin{array}{c}\text { Macula } \\
\text { status }\end{array}$ & $\begin{array}{c}\text { 1st vitrectomy } \\
\text { procedure }\end{array}$ & $\begin{array}{c}\text { Location } \\
\text { of RB }\end{array}$ & $\begin{array}{c}\text { PVD } \\
\text { Recurrence } \\
\text { (days) }\end{array}$ & $\begin{array}{c}\text { Recurrence } \\
\text { reason }\end{array}$ & $\begin{array}{c}\text { Decimal } \\
\text { PreVA }\end{array}$ & $\begin{array}{c}\text { Decimal } \\
\text { FinalVA }\end{array}$ & $\begin{array}{c}\text { Follow up } \\
\text { (M) }\end{array}$ \\
\hline 1 & OD & 82 & M & IOL & Off & 25G-TSV & Lower & Yes & 61 & Subretinal strand & 0.4 & 1.2 & 9 \\
2 & OD & 49 & F & IOL & Off & 25G-TSV & Upper & No & 11 & Original RB & 0.01 & 0.3 & 12 \\
3 & OS & 67 & F & Phakic & Off & Triple surgery & Lower & Yes & 17 & New RB & 0.03 & 0.3 & 12 \\
4 & OD & 49 & M & IOL & Off & 25G-TSV & Upper & Yes & 11 & Original RB & 0.5 & 0.8 & 6 \\
\hline
\end{tabular}

25G-TSV, 25-G transconjunctival sutureless vitrectomy; IOL, intraocular lens; PVD, posterior vitreous detachment; RB, retinal break; Triple surgery, phacoemulsification and aspiration, intraocular lens implant, and 25-G transconjunctival sutureless vitrectomy; VA, visual acuity.

a $95.2 \%$ anatomical success rate after the initial surgery, which suggests that 25G-TSV is as effective as that reported by Oshima et al and Miki et al. Although the follow-up period in our patients was $\geqslant 3$ months, the number of treated patients was sufficient for us to conclude that the effectiveness of 25G-TSV as a primary surgery for RRD is comparable with the success rates with 20G-PPV or scleral buckling. ${ }^{21,22}$

A RRD is usually associated with a posterior vitreous detachment, and our finding of $97.6 \%$ confirmed this. However, even with a PVD we could still find residual undetached cortical vitreous (RUCV) on the retinal surface in $20.7 \%(17 / 82)$ of the eyes when TA was used during the surgery. This low rate was unexpected as an undetached cortical vitreous has also been reported to be common (about 70\%) in eyes with a PVD and a rhegmatogenous retinal detachment. ${ }^{23,24}$ However, our cases with RUCV were not those with a small patch but those with a large circumferential area of vitreoretinal adhesion attached to the macula. This difference in the classification of a RUCV could explain this difference. For example, Chen et al reported that the percentage of eyes with a RUCV of multiple patches and large circumferential patch was $30.3 \%,{ }^{24}$ which is similar to the $20.7 \%$ in our series.

A postoperative epiretinal macular membrane developed in 6 of the 84 eyes $(7.1 \%)$ with a reattached retina, and all of these eyes had a preoperative PVD and no sign of RUCV. Thus, our results suggest that the development of a postoperative epiretinal macular membrane was most likely not caused by RUCV, but by other factors such as postoperative inflammatory cells or retinal pigment epithelial cells that escaped through retinal tears. $^{25}$

Campo et $a l^{26}$ reported that $6 \%$ of their patients who had undergone 20G-PPV for pseudophakic retinal detachments developed a macular pucker requiring surgery, $17 \%$ developed cystoid macular edema and $2 \%$ developed full-thickness macular holes. In our series, we found that $7.1 \%(6 / 84)$ of the patients developed a macular pucker, which is comparable with that reported by Campo et al. ${ }^{26}$ However, none of our patients developed cystoids macular edema or macular holes.
We attempted to remove as much of the peripheral gel including the gel around the original tear as possible by gel shaving. Although the 25-G sclererotomy port was most likely sealed by the herniation of the remaining gel, the technique of oblique sclerotomy and gel shaving with sclera compression allowed us to complete the vitrectomy without suturing. ${ }^{19,20}$ We suggest that an incomplete peripheral vitrectomy for RRD can lead to retinal redetachment and to PVR as our four redetached cases showed residual peripheral vitreous during the second vitrectomy.

Our findings indicate that the advantages of 25 G-TSV for RRD are; high rates of retinal attachment after the initial surgery, easier re-operation than that after 20G-PPV or scleral buckling because of the smooth ocular surface, and no adhesion of conjunctiva and scleral tissue. However, 25G-TSV for RRD had some points which might be a handicap; the inability to perform a complete peripheral vitrectomy, the limited number of surgical instruments and a greater requirement for wide angle viewing systems. Furthermore, compared with 25G-TSV for macula-on RRD, our results indicated that the disadvantages of 25G-TSV for macula-off RRD are (Table 2); longer operative times $(P=0.009)$, relatively low rate of initial reattachment $(P=0.08)$, relatively high rate of postoperative macula pucker $(P=0.14)$, and development of redetachments $(P=0.08)$.

Our study was not designed to determine why the rate of the retinal complications in the eyes with a preoperative macula-off RRD was higher than that in eyes with macula-on RRD. However, we suggest that one of the causes might be the longer operative time in addition to the preoperative macula-off condition.

A reduced IOP has been reported after 25G-TSV especially after a straight incision and in younger patients. ${ }^{27,28}$ This is important because postoperative hypotony is not uncommon after sutureless vitrectomy, which might allow bacterial entry into the vitreous through the sclerotomy sites. This could then lead to postoperative endophthalmitis. However, postoperative endophthalmitis after the sutureless vitrectomy can occur even in the absence of postoperative hypotony. ${ }^{29-34}$ Our results showed that 25G-TSV for RRD led to 
postoperative hypotony as reported,,$^{35,36}$ and the percentage of eyes was the same in eyes with preoperative macula-on RRD and with macula-off RRD.

An elevated postoperative IOP should be monitored particularly after the conventional 20G-PPV with fluidgas exchange. Although 23-G sutureless vitrectomy has a larger port than 25G-TSV, this appears to reduce the risk of extremely high pressure because the ports allow small amounts of gas to leak out when the IOP rises. ${ }^{37}$ Misra et $a l^{37}$ reported that none of their patients in the $23-G$ group had an IOP $>40 \mathrm{~mm} \mathrm{Hg}$ whereas four patients in the 20-G group had an IOP $>40 \mathrm{~mm} \mathrm{Hg}$. In our 84 patients, five $(6.0 \%)$ had a postoperative $\mathrm{IOP} \geqslant 35 \mathrm{~mm} \mathrm{Hg}$ including two cases with IOP $>40 \mathrm{~mm} \mathrm{Hg}$. These findings show that the sealing of the 25G-TSV port was tighter than that of the 23-G system and was too tight to allow gas to leak out of the eye. This indicates that high intraocular pressures can occur after 25G-TSV, and care should be taken to monitor all patients closely in the early postoperative period especially if a gas tamponade is used.

Although we found that there was a gradual improvement of vision in the macula-off RRD until 3 months, this is believed to be due to the recovery of macula function and ocular astigmatism. ${ }^{38}$ Our results indicated that combining cataract surgery with the vitrectomy did not significantly affect the visual improvement in our macula-off RRD cases. However, the cataract extraction may be a confounding factor when considering the visual acuity. A comparison of the visual acuity after RRD by 20G-PPV and by 25G-TSV without cataract surgery is needed to assess the efficacy of 25G-TSV on the improvement of vision and final visual acuity.

There are limitations of our study including the short follow-up period, small number of patients and a non-randomization of the patients. Nevertheless, our findings indicate that 25G-TSV for RRD is a feasible method and can lead to comparable retinal reattachment rates in addition to postoperative satisfactory ocular surface due to the sutureless technique. However, intra- and postoperative complications can develop, and a postoperative elevation of the IOP can occur after 25G-TSV in eyes with a preoperative macula-off detachment. There is no perfectly safe procedure for RRD, and even though the macula-on RRD did better in this study, this does not mean that they will never develop complications. A more frequent examination schedule may be very important after the 25G-TSV especially during the first 2 months considering the cases with postoperative redetachment. In addition, because there are patients who develop a redetachment after a few years after 20G-PPV, a follow-up of several years should be recommended after 25G-TSV.

\section{Summary}

\section{What was known before}

- There are few reports with a relatively large number of cases of RRD that used 25G-TSV as the primary procedure for treating the RRD.

\section{What this study adds}

- The purpose of this study was to determine the visual outcome and retinal complications of 84 consecutive eyes with a RRD treated by 25G-TSV by a single surgeon. Our findings indicate that 25G-TSV is a feasible treatment for RRD and leads to retinal reattachment rates comparable with those following conventional vitrectomy. However, intra- and postoperative retinal complications and postoperative elevation of the IOP can occur especially in eyes with a preoperative macula-off RRD.

\section{Conflict of interest}

The authors declare no conflict of interest.

\section{Acknowledgements}

This paper was presented partially at the Annual Meeting of the Japanese Society of Clinical Ophthalmology, Kyoto, October, 2007. Supported in part by research grants from the Ministry of Education, Culture, Sports, Science and Technology, Tokyo, Japan.

\section{References}

1 Heimann H, Bartz-Schmidt KU, Bornfeld N, Weiss C, Hilgers RD, Foerster MH. Scleral buckling versus primary vitrectomy in rhegmatogenous retinal detachment: A Prospective Randomized Multicenter Clinical Study. Ophthalmology 2007; 114: 2142-2154 e4.

2 Fujii GY, De Juan Jr E, Humayun MS, Chang TS, Pieramici DJ, Barnes A et al. Initial experience using the transconjunctival sutureless vitrectomy system for vitreoretinal surgery. Ophthalmology 2002; 109: 1814-1820.

3 Fujii GY, De Juan Jr E, Humayun MS, Pieramici DJ, Chang TS, Awh C et al. A new 25-gauge instrument system for transconjunctival sutureless vitrectomy surgery. Ophthalmology 2002; 109: 1807-1812; discussion 1813.

4 Rizzo S, Genovesi-Ebert F, Murri S, Belting C, Vento A, Cresti $\mathrm{F}$ et al. 25-gauge, sutureless vitrectomy and standard 20-gauge pars plana vitrectomy in idiopathic epiretinal membrane surgery: a comparative pilot study. Graefes Arch Clin Exp Ophthalmol 2006; 244: 472-479.

5 Kellner L, Wimpissinger B, Stolba U, Brannath W, Binder S. 25-gauge vs 20-gauge system for pars plana vitrectomy: a prospective randomised clinical trial. Br J Ophthalmol 2007; 91: 945-948.

6 Gonzales CR, Singh S, Schwartz SD. 25-Gauge vitrectomy for pediatric vitreoretinal conditions. Br J Ophthalmol 2009; 93: 787-790.

7 Scott IU, Flynn Jr HW, Dev S, Shaikh S, Mittra RA, Arevalo JF et al. Endophthalmitis after 25-gauge and 
20-gauge pars plana vitrectomy: incidence and outcomes. Retina 2008; 28: 138-142.

8 Kunimoto DY, Kaiser RS. Incidence of endophthalmitis after 20- and 25-gauge vitrectomy. Ophthalmology 2007; 114: 2133-2137.

9 Kapamajian M, Gonzales CR, Gupta A, Schwartz SD. Suprachoroidal hemorrhage as an intraoperative complication of 25-gauge pars plana vitrectomy. Semin Ophthalmol 2007; 22: 197-199.

10 Lai MM, Ruby AJ, Sarrafizadeh R, Urban KE, Hassan TS, Drenser KA et al. Repair of primary rhegmatogenous retinal detachment using 25-gauge transconjunctival sutureless vitrectomy. Retina 2008; 28: 729-734.

11 MA VONF, Kunjukunju N, Weber C, Ko G. 25-gauge sutureless vitrectomy 20-gauge vitrectomy for the repair of primary rhegmatogenous retinal detachment. Retina 2009; 29: $444-450$.

12 Shimada H, Nakashizuka H, Mori R, Mizutani Y. Expanded indications for 25-gauge transconjunctival vitrectomy. Jpn J Ophthalmol 2005; 49: 397-401.

13 Gonzales CR, Boshra J, Schwartz SD. 25-Gauge pars plicata vitrectomy for stage 4 and 5 retinopathy of prematurity. Retina 2006; 26: S42-S46.

14 Azad RV, Chanana B, Sharma YR, Vohra R. Primary vitrectomy versus conventional retinal detachment surgery in phakic rhegmatogenous retinal detachment. Acta Ophthalmol Scand 2007; 85: 540-545.

15 Quiroz-Mercado H, Garcia-Aguirre G, Ustariz-Gonzalez O, Martin-Avia J, Martinez-Jardon S. Perfluorocarbon-perfused vitrectomy using a transconjunctival 25-gauge system. Retina 2007; 27: 926-931.

16 Oshima Y, Ohji M, Tano Y. Surgical outcomes of 25-gauge transconjunctival vitrectomy combined with cataract surgery for vitreoretinal diseases. Ann Acad Med Singapore 2006; 35: 175-180.

17 Horozoglu F, Yanyali A, Celik E, Aytug B, Nohutcu AF. Primary 25-gauge transconjunctival sutureless vitrectomy in pseudophakic retinal detachment. Indian J Ophthalmol 2007; 55: 337-340.

18 Miller DM, Riemann CD, Foster RE, Petersen MR. Primary repair of retinal detachment with 25-gauge pars plana vitrectomy. Retina 2008; 28: 931-936.

19 Shimada H, Nakashizuka H, Mori R, Mizutani Y, Hattori T. 25-gauge scleral tunnel transconjunctival vitrectomy. Am J Ophthalmol 2006; 142: 871-873.

20 Lopez-Guajardo L, Pareja-Esteban J, Teus-Guezala MA Oblique sclerotomy technique for prevention of incompetent wound closure in transconjunctival 25-gauge vitrectomy. Am J Ophthalmol 2006; 141: 1154-1156.

21 Miki D, Hida T, Hotta K, Shinoda K, Hirakata A. Comparison of scleral buckling and vitrectomy for retinal detachment resulting from flap tears in superior quadrants. Jpn J Ophthalmol 2001; 45: 187-191.

22 Oshima Y, Yamanishi S, Sawa M, Motokura M, Harino S, Emi K. Two-year follow-up study comparing primary vitrectomy with scleral buckling for macula-off rhegmatogenous retinal detachment. Jpn J Ophthalmol 2000; 44: 538-549.
23 Kimura H, Kuroda S, Nagata M. Premacular cortical vitreous in patients with a rhegmatogenous retinal detachment. Retina 2004; 24: 329-330.

24 Chen TY, Yang CM, Liu KR. Intravitreal triamcinolone staining observation of residual undetached cortical vitreous after posterior vitreous detachment. Eye 2006; 20: 423-427.

25 Sheard RM, Sethi C, Gregor Z. Acute macular pucker. Ophthalmology 2003; 110: 1178-1184.

26 Campo RV, Sipperley JO, Sneed SR, Park DW, Dugel PU, Jacobsen $\mathrm{J}$ et al. Pars plana vitrectomy without scleral buckle for pseudophakic retinal detachments. Ophthalmology 1999; 106: 1811-1815; discussion 1816.

27 Byeon SH, Lew YJ, Kim M, Kwon OW. Wound leakage and hypotony after 25-gauge sutureless vitrectomy: factors affecting postoperative intraocular pressure. Ophthalmic Surg Lasers Imaging 2008; 39: 94-99.

28 Acar N, Kapran Z, Unver YB, Altan T, Ozdogan S. Early postoperative hypotony after 25-gauge sutureless vitrectomy with straight incisions. Retina 2008; 28: 545-552.

29 Taban M, Ufret-Vincenty RL, Sears JE. Endophthalmitis after 25-gauge transconjunctival sutureless vitrectomy. Retina 2006; 26: 830-831.

30 Acar N, Unver YB, Altan T, Kapran Z. Acute endophthalmitis after 25-gauge sutureless vitrectomy. Int Ophthalmol 2007; 27: 361-363.

31 Matsuyama K, Kunitomi K, Taomoto M, Nishimura T. Early-onset endophthalmitis caused by methicillin-resistant Staphylococcus epidermidis after 25-gauge transconjunctival sutureless vitrectomy. Jpn J Ophthalmol 2008; 52: 508-510.

32 Tan CS, Wong HK, Yang FP, Lee JJ. Outcome of 23-gauge sutureless transconjunctival vitrectomy for endophthalmitis. Eye 2008; 22: 150-151.

33 Chen JK, Khurana RN, Nguyen QD, Do DV. The incidence of endophthalmitis following transconjunctival sutureless 25- vs 20-gauge vitrectomy. Eye 2009; 23 : 780-784.

34 Hu AY, Bourges JL, Shah SP, Gupta A, Gonzales CR, Oliver SC et al. Endophthalmitis after pars plana vitrectomy a 20- and 25-gauge comparison. Ophthalmology 2009; 116: 1360-1365.

35 Von Fricken MA, Kunjukunju N, Weber C, Ko G. 25-gauge sutureless vitrectomy versus 20 -gauge vitrectomy for the repair of primary rhegmatogenous retinal detachment. Retina 2009; 29: 444-450.

36 Acar N, Kapran Z, Altan T, Unver YB, Yurtsever S, Kucuksumer $Y$. Primary 25-gauge sutureless vitrectomy with oblique sclerotomies in pseudophakic retinal detachment. Retina 2008; 28: 1068-1074.

37 Misra A, Ho-Yen G, Burton RL. 23-gauge sutureless vitrectomy and 20-gauge vitrectomy: a case series comparison. Eye 2009; 23: 1187-1191.

38 Kadonosono K, Yamakawa T, Uchio E, Yanagi Y, Tamaki Y, Araie M. Comparison of visual function after epiretinal membrane removal by 20 -gauge and 25-gauge vitrectomy. Am J Ophthalmol 2006; 142: 513-515. 